\title{
UNA TEORÍA LIBERTARIA PARA LA PAZ
}

\author{
GAETANO LEONE FLORES*
}

Fecha de recepción: 3 de junio de 2014.

Fecha de aceptación: 7 de octubre de 2014.

Resumen: Este artículo analiza la teoría libertaria de la paz y la guerra expuesta por Murray Rothbard en su famoso escrito: «War, Peace and the State» incluido como capítulo 2 de la sección 1 del libro recopilatorio de HansHermann Hoppe: The Myth of National Defense. Se argumenta en el mismo que la metodología utilizada para la elaboración de la teoría no fue del todo la más adecuada para poder abordar un tema tan complejo como este, que siempre salta a la luz del debate a la hora de criticar el agobiante intervencionismo estatal. Se analizan in extenso las implicaciones del camino escogido por el autor, proponiendo una metodología alternativa y exponiendo una serie de ideas seminales que sirvan para un posterior desarrollo de una teoría libertaria de la paz más completa y mejor integrada.

Palabras clave: Rothbard, Teoría Libertaria de la Paz, Guerra, Metodología.

Clasificación JEL: B25.

Abstract: This paper analyzes the libertarian theory for peace and war exposed by Murray Rothbard in his famous article: "War, Peace and the State» included in the chapter 2 of Hans-Hermann Hoppe's book: The Myth of National Defense. This paper argues that the methodology used for the making of the theory wasn't the most accurate one to approach a very complex subject like this one which always comes to the light of the discussion about the oppressive state intervention. It is analyzed in extenso the implications of the path chosen by the author, proposing an alternative methodology and exposing a series of seminal ideas for the further development of a more consistent and complete libertarian theory of peace.

* Business Analyst de Kimberly Clark Corporation y Vicepresidente Ejecutivo de Freskita Monarca Trading S.A. 
Key words: Rothbard, Libertarian Theory of Peace, War, Methodology.

JEL Classification: B25.

Los conservadores critican a los libertarios de falta de sentido práctico para afrontar los grandes problemas del mundo real: paz y guerra. Aducen que sus teorías abstractas se limitan a discutir temas superficiales tales como si la recogida de basuras debiera ser municipal o no. ${ }^{1}$

Rothbard, en contraparte, se propone a construir una teoría de la paz y la guerra basándose en el axioma de no agresión, que promulga que «el individuo solo podrá utilizar la violencia en defensa propia, contra quién lo esté agrediendo».

Así, el autor inicia su tesis con un simple escenario de individuos: A agrede la propiedad de B. ¿Está legitimado B para afectar a terceras personas en su defensa de A? No. El axioma de no agresión se antepone a cualquier justificación subjetiva del uso de la violencia en detrimento de personas inocentes.

Si A agrede a C como medio para defenderse de B está cometiendo un acto criminal. Se puede interpretar en un juicio la mayor culpabilidad de $\mathrm{B}$ pero no deja de ser un acto criminal el cometido por A hacia C, el cual puede defenderse en respuesta a esa agresión de A.

Ahora bien, Rothbard extrapola este principio a un escenario de guerra que por definición es un conflicto entre Estados, en sentido estricto, o brote de violencia entre grupos de personas en sentido general. Si A y sus secuaces agreden a B, y B y sus guardaespaldas buscan luego devolver la agresión, será del interés de la sociedad que este intento de repeler el ataque original de A sea exitoso (para establecer un precedente), e incluso, según el autor, hasta contribuirán financieramente a la causa. ${ }^{2}$ Pero

1 Así inicia el propio Rothbard su escrito «War, Peace, and the State» en alusión a las críticas recibidas por el famoso escritor y comentarista conservador William F. Buckley, Jr.

2 Rothbard falla al legitimar el financiamiento de terceros a la causa del individuo agredido, pues este hecho podría ser identificado o relacionado con la autoría 
esto no justifica ninguna agresión a terceras personas en el curso de su guerra justa. El axioma se mantiene.

Si B transgrede este axioma y agrede a terceras personas se convierte en un criminal tanto como A y se vuelve sujeto de las sanciones previstas para este tipo de actos. De hecho si la gravedad de su crimen es mayor (ej.: B en la defensa del robo de sus bienes por parte de A mata a $C$ para alcanzar su objetivo) su condición criminal es más grave.

Para Rothbard la cuestión no es si un individuo está en la facultad de usar la fuerza para prevenir la agresión contra otra persona (como marcan algunos slogans anti pacifistas), la cuestión es si, en esta prevención de agresión, está dispuesto ese individuo a agredir a gente inocente.

Al meterse en ese campo, el autor abre la puerta a un debate tan complejo, que ha sido justificador común del ejercicio de la justicia por parte del Estado (entendido in vox populi como una entidad neutral), como lo es el debate sobre aquellas personas desprotegidas que no pueden repeler una agresión en su contra por falta de capacidad y/o recursos. Sin embargo, en su reflexión, no «deja la llave» para «cerrar la puerta del debate», con mecanismos alternativos al Estado, para la defensa de esos grupos vulnerables.

Siguiendo el ejemplo de este ensayo, citado en la nota al pie número 3 de su edición en inglés, sobre el caso del individuo que usa la violencia para prevenir la violación de su hermana, ¿Qué pasa si aquella hermana violada, del slogan anti pacifista, no puede repeler a su agresor? ¿Si sus familiares repelen el ataque en su defensa, están faltando al axioma de no agresión, que se limita al escenario de defensa personal? ¿A quién se delega esta función de protección? Y una vez delegada, ¿Cómo facultar su ejercicio sin transgredir el axioma? Rothbard no aclara, con la metodología lógico-deductiva que utilizó en la proposición del axioma, estos importantes cuestionamientos que surgen a la luz de su análisis.

intelectual de una agresión, por parte de individuos no agredidos, contra un sujeto inocente en ese contexto, es decir en el contexto de una persona que no haya ejecutado ninguna agresión contra los patrocinadores económicos de la ofensa en su contra. 
La actitud que propone el autor a los libertarios, frente a la guerra, basándose en las premisas anteriores, es la de legitimar el uso de la violencia contra criminales, en defensa de los derechos individuales de vida y propiedad, siendo inaceptable violar los derechos de otra gente inocente. La guerra, en consecuencia, solo es permisible cuando el ejercicio de la violencia es rigurosamente limitado a los crímenes individuales.

Si extrapolamos la justificación de la guerra cuando se circunscribe a los crímenes individuales, al escenario de la hermana indefensa, podemos justificar la represalia por parte de los familiares, cuando se circunscribe al violador en mención. Sin embargo, en ambos casos se estaría violando el axioma de no agresión, porque ni el Estado tiene personalidad individual sujeta de ser agredida, ni los familiares de la hermana han sido directamente agredidos por el violador.

En este sentido, respetando la metodología lógico-deductiva con la que Rothbard quiere tratar este tema, nos vemos en la necesidad de reformular el axioma, para no transgredir las leyes de la lógica, y que se pueda aplicar a todas las circunstancias, o en su defecto, se debe reconocer la imposibilidad de defensa por parte de aquellas personas con menores recursos físicos, económicos, sicológicos o de cualquier índole, que los de sus agresores.

¿Nos estamos, tal vez, enfrentado a un problema de metodología, cuando queremos utilizar un análisis lógico-deductivo (válido para el estudio de la acción individual), en el campo de las instituciones sociales de carácter evolutivo, como son las que regulan la sociedad, con normas abstractas y consuetudinarias de convivencia, donde, siguiendo la línea de Hayek, debiéramos tal vez, utilizar una metodología diferente, como lo es el análisis histórico-evolutivo $?^{3} i \mathrm{O}$ se trata de un error intelectual en la concatenación de premisas para elaborar el axioma?

${ }^{3}$ El profesor César Martínez Meseguer, autor del libro La teoría evolutiva de las instituciones, interpreta la metodología de Hayek como una clara distinción entre tres niveles de estudio: La Acción Humana, las Relaciones de Intercambio entre individuos, y las Instituciones Sociales. Para los dos primeros considera el análisis lógicodeductivo como el más apropiado en virtud de que todos los individuos gozan de una estructura mental lógica y por lo tanto es posible deducir los principios de su actuación, a partir de los cuales, en una concatenación de premisas verdaderas, elaborar 
Podemos replantear el axioma como «todo individuo que agreda a cualquier otro individuo, comete un acto criminal, sujeto de ser repelido proporcionalmente, por cualquier miembro de la sociedad, o entidad que ésta designe para el propósito». O tal vez, «todo individuo que agrede a cualquier individuo automáticamente pierde su derecho a no ser agredido, en la misma proporción que agredió». En cualquiera de los casos, vemos como se puede aplicar perfectamente la guerra circunscrita a los criminales individuales, o la protección de la hermana indefensa, circunscrita al criminal violador, sin transgredir el axioma.

Sin embargo, las leyes de la lógica saltan inmediatamente para señalarnos una contradicción: al agredir al agresor en defensa propia, o en defensa de una tercera persona, nos convertimos en agresores, y en consecuencia, según el propio axioma, también nos convertimos en sujetos a ser agredidos, en un entorno caótico, donde la no agresión queda totalmente desamparada. Vemos como el primer axioma funcionaba mejor para limitar la violencia a la defensa propia, pero dejaba desprotegidos a los grupos vulnerables, en contraste, estas reformulaciones del axioma, amparan a los grupos vulnerables, pero otorgan carta abierta a la violencia desmesurada.

Podemos continuar haciendo ejercicios intelectuales en torno a esta metodología lógico-deductiva, tratando de perfeccionar el axioma, pero inevitablemente vamos a caer en la necesidad de introducir matices subjetivos, donde quepan las más variadas justificaciones en pro y en contra de la intervención del Estado.

Siguiendo otra vía, podemos mejor, hacer uso de la Institución del Derecho y la Justicia para normar estos conflictos con leyes abstractas y consuetudinarias, de creación no deliberada. Al referirme a éstas, no me refiero al Derecho Positivo impuesto de forma coactiva por el Estado, que no solo ha fallado a la hora de

\footnotetext{
las teorías más complejas. Para el tercer nivel, en cambio, propone una metodología histórico-evolutiva, en virtud de que no se trata de órganos de estructura lógica, sino de órdenes espontáneos que surgen como resultado no deliberado de la interacción de millones de individuos, durante un dilatado periodo de tiempo, que superan con mucho las limitaciones de la mente individual, y que sirven como guías de comportamiento para el desarrollo ulterior de la sociedad.
} 
proporcionar las más elementales garantías a la vida y propiedad de los individuos, sino que, incluso, se ha convertido en el mayor agresor de estos derechos, me refiero mas bien, al Derecho y la Justicia en la más pura tradición romana clásica, con leyes abstraídas del uso cotidiano por juristas que ejercían su profesión libremente, y que servían de guía al juez para resolver los conflictos entre dos o más conciudadanos. ${ }^{4}$

Para entender mejor esta propuesta podemos hacer una analogía con la institución del lenguaje: el español por ejemplo. Nuestro idioma es el resultado de la interacción de miles de individuos durante un dilatado periodo de tiempo, que en su afán de comunicarse unos con otros, fueron desarrollando un lenguaje verbal y escrito que fue evolucionando con el pasar de los años. Al nacer hoy, un nuevo individuo, en un país hispano-hablante, a través de su familia y la interacción con el resto de la sociedad, aprende este lenguaje, que a su vez, continuará evolucionando con los nuevos usos que le den las personas de su generación, y que será retransmitido en esa renovada versión a las generaciones subsiguientes, para continuar en un proceso evolutivo sin fin.

Los lingüistas, por su parte, son los estudiosos del lenguaje, quienes se encargan de abstraer del uso que los hispano hablantes le dan a su idioma, el vocabulario y las leyes gramaticales que mejor servirán para la comunicación entre todos, los mismos que serán publicados a través de los órganos correspondientes ${ }^{5}$ y que servirán de guía para poder comunicarnos de manera más fluida y efectiva. Cabe recalcar, que estas leyes no son impuestas y su uso responde exclusivamente a la idoneidad de las mismas en su función de mejorar la comunicación.

Volviendo al Derecho, el respeto a la vida y a la propiedad privada, son el resultado de la interacción de miles de individuos,

\footnotetext{
4 Para profundizar en la tradición jurídica romana clásica es imprescindible la obra de Bruno Leoni: Freedom and the Law, traducida al español por Unión Editorial bajo el título La libertad y la ley.

5 Nos referimos para el caso del idioma castellano al trabajo que cumple la Asociación de Academias de la Lengua Española integrada por 19 Academias Latinoamericanas, 1 Academia Filipina, 1 Academia Norteamericana y la Real Academia Española.
} 
durante un dilatado periodo de tiempo, que en su afán de convivir y prosperar, fueron descubriendo estos principios fundamentales para el desarrollo de la sociedad. Aquellas sociedades que más rápido descubrían y adoptaban estos principios, prosperaban más rápido y se desarrollaban mejor, que aquellas que no los adoptaban. ${ }^{6}$ Los juristas, por su parte, eran los estudiosos del Derecho, quienes se encargaban de abstraer esas normas de convivencia para que el juez pudiera impartir justicia.

Ahora bien, una alternativa racionalista a esa institución de emergencia espontánea de los diferentes idiomas del mundo, sería el Esperanto. Lengua creada en 1887 por el oftalmólogo de origen judío, Lázaro Zamenhof, con la esperanza de que se convirtiera en el lenguaje del mundo, para llevar a cabo este propósito, Lázaro extrajo vocabulario y reglas gramaticales de muchos idiomas, con el fin de ser una lengua aglutinante. Sin embargo, hoy en día, menos del 0,03\% de la población mundial, lo habla. Siguen siendo los idiomas surgidos espontánea y evolutivamente los que han perdurado en el tiempo.

Si extrapolamos esa alternativa racionalista del idioma a la institución del Derecho, nos encontramos con el Derecho Positivo, entendido como aquel que instituye por decreto cuales son las normas de convivencia que dirigen la sociedad. Las leyes dejan de emanar de la sociedad hacia los organismos de Justicia que median los conflictos, para emanar directamente del razonamiento de los gobernantes de turno a través del Estado, quién a su vez, ejerce como organismo monopólico de Justicia. ${ }^{7}$

${ }^{6}$ Los romanos eran muy conscientes de estos principios que les permitieron erigirse como uno de los Imperios más fuertes de la Historia por sobre aquellos pueblos que ellos mismos denominaban bárbaros, cuyo sistema de Derecho y nivel de desarrollo era muy inferior. Sobre el origen de la caída del Imperio Romano en torno a causas endógenas más que de invasiones bárbaras son de interesante consulta las reveladoras aportaciones de Ludwig von Mises en Human Action, The Scholar's Edition, Mises Institute, Alabama 2008, pp. 761-763, y Peter Temin en su artículo «The Economy of the Early Roman Empire», Journal of Economics Perspectives, vol. 20, n.ำ 1, invierno 2006, pp. 265-290. Existe una traducción al castellano del artículo, realizada por Giovanna Zanella, publicada con el título de «La Economía del Alto Imperio Romano», en Procesos de Mercado, vol. 6, n.․ 2, otoño 2009, pp. 265-287.

7 Robert Nozick en su clásico Anarquía, Estado y Utopía nos ofrece una tercera alternativa a la del derecho en la tradición clásica romana al servicio de los juristas 
No es propósito de esta crítica extendernos en los errores que conlleva dejar a los políticos de turno el monopolio de la ley. Los ejemplos de la manipulación de esta Institución, al servicio de los grupos de interés que rodean a los gobiernos son incontables. Por el momento nos limitaremos a destacar que:

1. El objeto de estudio de Rothbard en este ensayo sobre la paz y la guerra corresponde al de instituciones sociales como el Derecho y la Justicia.

2. La naturaleza de estas instituciones sociales superan con mucho la capacidad limitada de tiempo, espacio, información y comprensión de la mente humana.

3. Por la propia naturaleza de estas instituciones, la ley no puede emanar de la mente de los políticos de turno en el ejercicio de su poder en el Estado.

4. Sin embargo, tampoco puede emanar de la mente de ningún teórico, fuere de la línea que fuere, utilizando la metodología lógico-deductiva para la elaboración de axiomas que, como hemos demostrado más arriba, no corresponden a todas las circunstancias.

5. La metodología más adecuada para el estudio de este tipo de instituciones es, por contraste, la histórico-evolutiva, que consiste en abstraer los principios universales de estos órdenes espontáneos que han surgido en el tiempo, principios que a través de continuos procesos de prueba y error y por el mecanismo de imitación, han perdurado por ser los más útiles para el desarrollo de la sociedad, y que deben ser comprendidos en los contextos en los que han surgido, con un análisis constante de su interminable evolución.

profesionales y el derecho positivo como lo conocemos ahora ejercido monopólicamente por el Estado. Se trata de un minarquismo resultante de la evolución de las necesidades de la sociedad a concentrar su sistema de defensa y agencia judicial en una única agencia privada (por las ventajas que supondría su tamaño en la cobertura), convertida en ese contexto en un Estado de facto. Al margen de los juegos racionalistas de imaginar cómo se organizaría la provisión de estos servicios vitales para la convivencia de una sociedad, en el que podemos poner en contraposición, muchos ejemplos privados de amplia cobertura a través de la cooperación (y no concentración) de empresas, este artículo trata de mantenerse dentro los límites de la teoría económica. 
6. Para defender la libre evolución de estas instituciones que, lamentablemente por diversos motivos, han sido intervenidas por intereses particulares, ${ }^{8}$ podemos apoyarnos en la teoría de la función empresarial, ${ }^{9}$ desarrollada, ahora sí, con la metodología lógico-deductiva, propia de su objeto de estudio: la acción humana y sus relaciones de intercambio.

Continuando con la aproximación de Rothbard hacia la guerra, nos encontramos con la pregunta que salta rápidamente en su análisis, ¿Cuántas guerras han cumplido el criterio de circunscribirse a los autores del crimen? La respuesta es: probablemente ninguna. Luego el autor pasa a criticar la posición de los conservadores respecto del desarrollo de armas de ataque masivo, para quienes éstas se tratan solo de una diferencia de "grado» más no de una diferencia de «clase», con respecto a las sencillas armas

8 La institución del Dinero y la Justicia son dos claros ejemplos de la intervención deliberada. Para profundizar en la naturaleza de estas instituciones son muy interesantes el trabajo de Carl Menger sobre el origen del dinero, y Friedrich Hayek y Bruno Leoni sobre la manipulación de la ley. Afortunadamente, por no representar un lucro, la institución del Lenguaje no ha sido mayormente intervenida y ha evolucionado libremente, salvo contadas excepciones en que ha sido utilizada como instrumento de dominación cultural, provocando en algunos casos, furibundas reacciones de sus parlantes. Lamentablemente, por su naturaleza más abstracta, ha sido difícil comprender por la población general, la manipulación del dinero, no teniendo la misma reacción en defensa del mismo por parte de sus usuarios. La manipulación de la ley, si ha sido denunciada en muchas ocasiones, sin embargo los esfuerzos se han concentrado en cambiar de administrador del monopolio de la justicia y no en cambiar el sistema que impide su libre evolución.

9 «El ser humano tiende a descubrir la información que le interesa, por lo que, si existe libertad en cuanto a la consecución de fines e intereses, estos mismos actuarán como incentivo, y harán posible que aquel que ejerce la función empresarial motivada por dicho incentivo perciba y descubra continuamente la información práctica relevante para la consecución de los fines propuestos. Y al revés, si por cualquier razón se acota o se cierra el campo para el ejercicio de la empresarialidad en determinada área de la vida social (mediante restricciones coactivas de tipo legal o institucional), entonces los seres humanos ni siquiera se plantearán la posibilidad de lograr o alcanzar fines en esas áreas prohibidas o limitadas...» Jesús Huerta de Soto, Socialismo, cálculo económico y función empresarial, 4. ․ ed., Unión Editorial, Madrid 2010, pp. 74-75. Son los individuos quienes enriquecen con su actuación a las instituciones, si los dejamos actuar en libertad, éstas evolucionarán, si coartamos su libertad, la evolución de las instituciones se limitará a la voluntad de unos cuantos, no reflejará un orden espontáneo e incluso podría llegar a convertirse en contraproducente a los intereses generales. 
de la era anterior. En este sentido, nos suscribimos plenamente a su contra argumentación, donde destaca que no es lo mismo un tipo de arma como puede ser el arco y flecha, para atacar un objetivo individual, que los tipos de armas como la bomba nuclear, donde difícilmente se pueda discriminar el objetivo en una destrucción masiva y los «colaterales» sean muchas vidas inocentes, en cuyo caso, concluye Rothbard, su uso constituye un crimen de lesa humanidad, para el cual no hay justificación alguna.

Así, en una visión libertaria, no hay espacio para el adagio que sostiene que no son las armas en sí, sino la capacidad de utilizarlas, lo que determina los estados de paz y guerra, precisamente porque esa capacidad conlleva el riesgo de no poder ser utilizada selectivamente, y representa una seria amenaza para la propia supervivencia de la humanidad. Observando este riesgo, la política libertaria apunta hacia un desarme y reconoce la urgencia de prevenir la aniquilación masiva.

Llega el punto donde el autor incorpora plenamente al Estado en el análisis, definiéndolo como el grupo de personas que detentan el monopolio del uso de la violencia a lo largo de un territorio. Para Rothbard, es el Estado la única organización que obtiene ingresos del uso de la violencia: «todas las organizaciones restantes y sus individuos (excepto si se les delega ese derecho por el Estado) pueden obtener riqueza solo mediante producción pacífica e intercambio voluntario de sus respectivas producciones.»

Si bien pudieran surgir, ingenuamente, cuestionamientos a esta afirmación, en torno a las empresas privadas de seguridad, que en efecto ganan dinero por el uso de la violencia, es claro aquí que éstas forman parte de esa excepción delegada por el Estado, que es en última instancia la única institución legalmente facultada para el ejercicio de la violencia, y la única capaz de transmitir esa facultad a quienes los gobernantes de turno estimen conveniente. Sin embargo, sí le faltó incluir a los individuos y grupos de individuos denominados antisociales, que operan al margen de la ley y que aún en presencia del Estado, también obtienen ingresos del uso de la violencia.

El autor señala el uso de la violencia por parte del Estado, que identifica con el cobro de impuestos para obtener sus ingresos, 
como el elemento clave de su poder, a partir del cual somete a los individuos y expande su intervención a todas las esferas posibles, al punto de que hoy en día, no se concibe una sociedad, en la que sean otras entidades, quienes provean bienes y servicios fundamentales, como la policía, el servicio judicial, las carreteras, la emisión de dinero, el correo postal, etc.

Muy probablemente, pocos son los que suscriban la idea de identificar el cobro de impuestos con la violencia, precisamente porque lo relacionan con la fuente de ingresos que financia el orden público, canalizado a través del Estado, dirigido por un gobierno elegido democráticamente, al menos en la mayoría de los países occidentales. Sin profundizar en el mito de la democracia como un sistema que garantice las libertades individuales, que dicho sea de paso, no compartimos, nos bastará con señalar que:

1. Todos los individuos están obligados a pagar impuestos, incluso en contra de su propia voluntad. Quienes se abstengan de hacerlo serán considerados como individuos que actúan al margen de la ley, y serán condenados con sanciones que incluyen la expropiación de sus bienes.

2. El importe a pagar por concepto de impuestos no ha sido convenido previamente entre la entidad que lo está cobrando y el individuo que lo está pagando. Es un importe determinado unilateralmente por el Estado, con efecto coactivo inmediato, sobre todos los individuos que conviven en el territorio de su jurisdicción.

3. Al no existir el derecho a la resistencia de los individuos, ni en el pago de impuestos, ni en la determinación del importe a pagar, el Estado los está claramente violentando.

4. En la mayoría de los países occidentales, tal vez en mayor grado todavía en los países orientales, los Estados no se limitan al cobro de impuestos para la provisión de seguridad, sino que, amparados en el monopolio de la Justicia, se arrogan legalmente muchas funciones adicionales, que incluyen la propiedad y la provisión exclusiva de los más variados bienes y servicios. ${ }^{10}$

10 Basta con revisar el arsenal de regulaciones de los gobiernos de la Unión Europea o Estados Unidos, en todos los ámbitos de la vida de sus ciudadanos, para notar 
5. En esta arrogación de nuevas funciones las necesidades administrativas crecen de forma paralela, demandando más colaboradores y más gastos, con un criterio denominado social, en lugar de un criterio económico, es decir, las pérdidas o ganancias generadas como resultado del ejercicio, están supeditadas a las valoraciones subjetivas de la utilidad a la sociedad, que representa las prestaciones del gobierno, según el criterio de los propios gobernantes. ${ }^{11}$

6. Para que una empresa tenga éxito en el libre mercado, hace falta que los bienes y servicios que provea, generen valor en sus clientes, por lo que solo permanecen y se desarrollan, aquellas que crean riqueza en la sociedad, y aquellas que no, tendrán que liquidar sus inversiones y redirigir sus recursos. En esta provisión de bienes y servicios, ningún individuo está obligado a adquirirlos, y solo se hará con ellos en la medida que valore más lo que recibe que el importe que paga por ellos.

7. Las necesidades del mercado representan oportunidades de ganancia y el empresario en su ánimo de lucro buscará satisfacer estas necesidades, así, si bien no podemos imaginar exactamente cómo serán provistos los bienes y servicios que actualmente monopoliza el Estado, porque al fin y al cabo dependerá

la amplia interferencia del Estado en todos los niveles. Un claro ejemplo de la propiedad exclusiva de ciertos bienes y servicios, lo encontramos en América del Sur, donde el Estado Chileno es propietario del cobre, el Estado Boliviano es propietario del gas, los Estados de Ecuador y Venezuela son propietarios del petróleo, y así podemos continuar en una interminable lista de apropiaciones.

${ }^{11}$ El premio Nobel de Economía, Milton Friedman, explicaba en una de sus lecciones, que existen 4 formas de gastar el dinero:

1. Gastar tu propio dinero, en ti mismo: Siendo muy cuidadoso de lo que gastas y asegurándote sacarle el máximo provecho a lo gastado.

2. Gastar tu propio dinero, en otro: Siendo cuidadoso de lo que gastas, pero con menos preocupación, por cuánto obtiene el otro, de la compra recibida.

3. Gastar el dinero de otro, en ti mismo: Asegurándote de obtener buenos productos por lo que gastas, sin preocuparte demasiado por cuánto gastas.

4. Gastar el dinero de otro, en otro: Sin el nivel de cuidado como si fuera tu propio dinero, o el nivel de pasión, dedicación y conocimiento como si lo gastaras para ti mismo y no para otros.

Pues bien, el gasto del Estado se encuentra perfectamente enmarcado en el $4 .{ }^{\circ}$ nivel que cita Friedman. 
de la creatividad del empresario en su oferta, sí cabe fácilmente imaginar qué será provisto en las actuales circunstancias, y que solo pervivirán en el mercado aquellos que mejor provean dichos servicios.

Rothbard, profundiza en este análisis del monopolio del uso de la fuerza en un territorio, por parte del Estado, para explicar cómo se deriva de ahí, la aparente paz. Y es que no existe violencia en varios sentidos, más que en la dirección Estado-Ciudadanía, mientras ésta no sea opuesta por los ciudadanos, salvo en el caso de las contadas revoluciones, se habla de un estado de paz.

Si bien Rothbard nota que existe el monopolio del uso de la fuerza, de los Estados, sobre sus territorios de jurisdicción, nota también, que no existe un supra Estado, con el monopolio del uso de la fuerza, sobre el mundo entero. De ahí, que se derive, una suerte de «anarquía» entre los diferentes Estados. El autor no encuentra una consistencia entre la posición de los conservadores, que critican la posible abolición del monopolio de la fuerza por parte de un Estado dentro de un determinado territorio, tachándola de lunática, sin someterse a su vez al monopolio de la fuerza sobre el mundo entero, de un ente supremo, desestimándola en nombre de la soberanía nacional. De ahí que, de la violencia abierta, es decir, de un conflicto entre dos o más Estados, se derive la denominada guerra internacional.

Ahora bien, existen diferencias importantes, que señala Rothbard, entre un estado de guerra interestatal, por un lado, y las revoluciones contra el Estado o conflictos entre individuos privados, por el otro:

1. Área geográfica - En las revoluciones, la ciudadanía y el Estado tienen el conflicto dentro del mismo territorio. La guerra inter estatal ocurre entre dos o más grupos, cada uno con el monopolio del uso de la fuerza, sobre un territorio diferente. De ahí, que el objetivo de uso de las armas de destrucción masiva, sea mucho más grande, en el segundo caso.

2. Discriminación de objetivos - Es más fácil para los revolucionarios y el Estado, determinar los enemigos dentro de su mismo territorio y evitar agresiones colaterales. Cuando la guerra 
es entre Estados, es mucho más difícil discriminar los objetivos de la agresión y evitar efectos colaterales en civiles inocentes.

3. Extensión de la enemistad a todos los habitantes del Estado en guerra: Ya que el Estado posee el monopolio del uso de la fuerza y la ley, tiene la facultad de movilizar a todos los habitantes y recursos dentro de su territorio, convirtiéndolos a todos, al menos temporalmente, en enemigos del otro Estado en conflicto.

4. Financiamiento - Los Estados financian sus guerras con los impuestos de los contribuyentes, mientras que los revolucionarios solo pueden financiarse con las contribuciones del público. En la esfera privada, el conflicto solo lo financian las partes interesadas, con su propio dinero.

En suma, las guerras entre Estados involucran a más gente inocente y dilapidan recursos ajenos a su interés, mientras que los conflictos privados se acotan a las partes involucradas. Aún cuando no estamos de acuerdo en la posición del autor de justificar ciertas revoluciones, pues muchas de ellas acaban desviando su objetivo inicial y sus líderes terminan embriagándose de poder y sometiendo de manera violenta a los individuos para que financien su causa, no podemos dejar de comentar que éstas son solo consecuencia de la privación de la libertad por parte del Estado, y deben a él, su origen.

En las circunstancias actuales, con los Estados y sus monopolios del uso de la fuerza sobre el territorio de su jurisdicción $\mathrm{da-}$ dos, Rothbard llama a los libertarios a presionar a sus gobiernos para que limiten el uso de la violencia al interior, es decir, para que eviten totalmente la guerra entre Estados, y si llegase a surgir un conflicto de esas características, negocien la paz o declaren cese al fuego tan rápido como sea posible.

Esto incluye el escenario en el que un Estado B confisque la propiedad privada o agreda la integridad física, dentro de su territorio de jurisdicción, a un ciudadano visitante de un Estado A. $Y$ es que si se admite el monopolio del uso de la fuerza por parte de un Estado sobre un territorio, ese mismo criterio debe aplicarse para impedir que un Estado ajeno a su territorio, ejerza violencia donde otro Estado ostente dicho monopolio. De ahí que, si 
un ciudadano de un Estado A decide viajar o invertir en un Estado B, las consecuencias de esta acción deben estar circunscritas al ciudadano y no a todo el Estado al que pertenece.

No hay una defensa certera ante la amenaza de una bomba nuclear, ni Estado que la garantice. Con independencia de las causas que la provoquen, debe ser del interés de todo ciudadano el evitar la guerra entre Estados a cualquier coste. Sin irnos tan lejos como nos lleva el artículo, por la realidad propia de Estados Unidos, a la que se refiere el autor, basta con repasar la ineficiencia del Estado para defendernos de los robos, los hurtos, los asesinatos y demás crímenes atroces con los que convivimos a diario, para notar que no nos encontramos ante un sistema eficiente de defensa, y si bien, en muchos países occidentales, nos encontramos con alternativas privadas más eficientes para nuestra seguridad particular, no así en el caso de guerras entre territorios enteros, cuya seguridad esta monopolizada por el Estado.

Llegados a este punto, Rothbard nos propone un escenario donde, a pesar de la oposición civil, la guerra se ha iniciado y los Estados no buscan negociar la paz. ¿Cuál debería ser la posición libertaria? Con las reglas del juego dadas, se puede tratar de reducir a lo mínimo posible el número de civiles inocentes afectados en el curso de la guerra, para ello, se dispone de las «leyes de guerra»y «leyes de neutralidad». Las leyes de neutralidad están orientadas a confinar la guerra dentro de los países participantes, excluyendo de la agresión a los no participantes. Será de interés libertario, mantener a los países neutrales en estado neutral. Las leyes de guerra están orientadas a limitar lo máximo posible la violación de los derechos de los civiles no combatientes, por parte de los Estados. De ahí que, deslegitimen la posibilidad de una guerra sin identificación plena de los objetivos y por supuesto, el uso de armas de destrucción masiva.

Como corolario de esta política libertaria para la coexistencia pacífica entre países, propuesta por el autor, emerge la rigurosa abstención de un Estado de recibir ayuda externa de cualquier tipo, de otro Estado. Aunque aparentemente conmocione en primera instancia al lector, esta declaración de Rothbard señala dos puntos muy interesantes a considerar: 
1. Cualquier ayuda de un Estado A hacia un Estado B, ha sido ejecutada con aportes del contribuyente del Estado A, es decir, estimula la agresión fiscal. Profundizando en esta observación, podemos añadir que ese dinero, que en teoría era para mejorar el bienestar del Estado donde vive el contribuyente, se convierte en un gasto dirigido a otros fines, y se traduce en desinversión local o aumento de la presión fiscal para cubrir su falta.

2. En una coyuntura de revolución, se agrava la represalia del Estado B a su propia gente. Aún si la ayuda es dirigida a los revolucionarios, también debe ser condenada por el origen que tiene ese dinero: los contribuyentes del Estado A. Podemos agregar aquí que, con independencia de la causa que se está financiando, ningún Estado conoce mejor la realidad interna del país en cuestión que el propio gobierno de ese Estado. Además, también es condenable la ayuda externa a la revolución, por ser una intromisión en asuntos internos de otro territorio.

Finalmente, Rothbard aplica su teoría libertaria al problema del Imperialismo, entendido como la agresión de un Estado A contra los ciudadanos de un Estado B y la consecuente imposición de las leyes del Estado A. En este escenario, la defensa de los ciudadanos del Estado B está perfectamente legitimada, siempre y cuando se circunscriba a repeler a los agresores del Estado A.

Se ha sostenido que el Imperialismo del Oeste, sobre los países subdesarrollados, está justificado por garantizar en mejor medida, los derechos individuales de los ciudadanos de aquellos territorios, que lo que podrían garantizar sus gobiernos nativos. El autor derriba este mito argumentando que, juzgar lo que debería ser el status quo es meramente especulativo, mientras que la intromisión es muy real y perjudicial. Además, el libertario debe concentrarse primero en el contribuyente que es sometido a pagar impuestos para financiar conquistas y mantener la burocracia imperial, antes que en los potenciales beneficios de otros ciudadanos, cuyo territorio de jurisdicción no les corresponde.

¿Significa la oposición a toda guerra, que los libertarios deben permanecer impávidos ante otros regímenes injustos? Rothbard dice que no. A continuación nos plantea un escenario en el que el hipotético Estado de «Waldavia» ataca «Ruritania» y anexa la 
parte oeste de su país. ¿Cómo consiguen los habitantes de Ruritania reunificarse con sus hermanos del este? Si la negociación pacífica, en primera instancia, no funciona, y los libertarios de Waldavia no consiguen presionar a su gobierno para que abandone la conquista de Ruritania en segunda instancia, el autor mantiene la postura de deslegitimar una guerra en contra del Estado de Waldavia, siendo las únicas rutas legítimas, el levantamiento revolucionario de los grupos oprimidos y la ayuda de grupos privados ruritanios, a los rebeldes del oeste, en forma de equipos o personal voluntario.

Muy poco convincente se ha mostrado Rothbard en el tratamiento del problema de la defensa de los conciudadanos de un determinado Estado ante la agresión de un Imperio externo. Y esto es así por el error citado más arriba, de querer construir toda una teoría, propia de instituciones sociales como el Derecho y la Justicia, a través de una metodología lógico-deductiva, propia del estudio de la acción individual. Cae así, en el riesgo de ser plenamente descartado por los fervientes defensores de la intervención del Estado, e incluso, de los mismos libertarios, en asuntos de defensa nacional ante amenazas externas. Seguramente, los polacos, por ejemplo, no coincidirán con esta teoría luego de haber experimentado la invasión de la Alemania Nazi.

Proponemos una lectura alternativa al problema en cuestión, ¿En ausencia de un Estado con el monopolio de la violencia sobre un territorio, existirían conflictos de la naturaleza y magnitud de los conflictos que han existido a lo largo de la historia? La respuesta es no. En una sociedad de derecho privado, los conflictos estarían limitados a las diferencias que surjan entre individuos o grupos de individuos, siendo las diferentes alternativas del mercado para dirimir esas diferencias, quienes resuelvan los conflictos puntuales que se susciten. No existiría la tendencia de otros individuos, al margen de las partes interesadas, en entrar al conflicto y mucho menos financiarlo con su dinero. En una sociedad de plena propiedad privada, los conflictos estarían limitados a las agresiones que surjan contra las bien delimitadas propiedades de los individuos, sin tener que extenderse a otras propiedades privadas que no hayan sido agredidas. En una sociedad donde el ser humano sea la unidad de medida y no entidades abstractas 
sin personalidad física, no se apelaría en el surgimiento de un conflicto, a la reacción colectiva, ni se sometería a los demás a unirse a la causa, que no les compete ni les afecta.

Desde luego, con un análisis histórico-evolutivo previo de las instituciones sociales que han permitido el desarrollo y prosperidad de la sociedad, podemos pasar a un análisis lógico-deductivo posterior, para argumentar por qué el individuo, en su afán de alcanzar sus fines personales, contribuye inintencionadamente al progreso de todos, integrando así una teoría consistente con los preceptos libertarios, de la paz y la cooperación humana.

No es propósito de este análisis crítico, aplicar la teoría de la ausencia del monopolio de la violencia por parte del Estado, como garantía sine qua non de la paz, a cada evento histórico de guerra o posible suceso de atentado contra la libertad individual, bastará con dejar por sentado que:

1. No se puede deducir lógicamente a partir de un axioma, una teoría de la paz y la guerra y ser consistente con la metodología para poder aplicarla de forma universal. Hay que recurrir a otra metodología cuando se trata de órdenes espontáneos y es la histórico-evolutiva que nos propone Hayek. ${ }^{12}$

2. El riesgo de conflictos es tan inerradicable como inerradicable es el desconocimiento del futuro actuar de cada ser humano, pero la naturaleza de los mismos, cuando se limita a la esfera individual, es infinitamente menos agresiva, que la naturaleza de un conflicto entre Estados, donde los gobernantes se arrogan ejercer la violencia en el nombre de todos y con los recursos de todos.

12 «El método histórico-evolutivo, único adecuado para el estudio de las instituciones sociales, no consiste solo en una recopilación de datos del pasado (Historia, Estadística...), sino que trata de estructurar dichos datos, comprobando las diferentes fases evolutivas experimentadas por cada institución según el contexto histórico en que se han desarrollado, analizando las etapas de surgimiento, la filtración y asimilación de información que acumulan, las influencias sufridas en su desarrollo, las manipulaciones intervencionistas del proceso y sus adulteraciones, así como el estudio de las vías más adecuadas para su correcto desarrollo, intentando buscar soluciones a los errores del pasado.» César Martínez Meseguer, La teoría evolutiva de las instituciones, 2. ${ }^{a}$ ed., Unión Editorial, Madrid 2009, p. 171. Recordemos la labor de los lingüistas en la lengua española y los juristas en la justicia romana. 
3. Jugar a imaginar cómo se ofrecerían los servicios de justicia y defensa desde la esfera privada es caer en construcciones racionalistas propias de quién pretende saber el futuro actuar de todos los individuos, algo imposible. Lo que si podemos imaginar, con la ayuda de la praxeología, es que donde haya una necesidad para la sociedad, que represente una oportunidad de ganancia por ser cubierta, esta necesidad será atajada por la iniciativa empresarial, inherente a la naturaleza humana.

4. Permanentemente el Estado ha demostrado el alto coste de sus operaciones y la ineficacia para garantizar nuestra seguridad. En un mercado libre, recordemos que solo sobreviven, aquellas empresas que proveen los servicios, cuales quieran que fueren, a menor coste y con mejor calidad.

5. Si un individuo quiere matar a otro individuo, por el motivo que fuere, muy seguramente logrará hacerlo, al margen de las medidas preventivas del Estado, que no puede hacerse con la información de actos criminales, si ésta aún no se ha generado, y solo puede actuar de manera reactiva. Si está en la moral y en la ética del individuo no matar, no es porque lo dice una ley o una constitución, de hecho ese mismo individuo puede no conocer el artículo donde se prohíbe ese acto criminal. Probablemente, no mata, porque se crió en el seno de una familia y/o una sociedad donde se le transmitió esos valores.

Concluye Rothbard el artículo rescatando la importancia de la eliminación de los métodos de aniquilación masiva en particular, y el desarme militar de los Estados, hasta llegar a un limitado nivel policial, en general. Agrega que es la guerra, el evento que promueve la tiranía del Estado, al ser su máxima expresión de poder y control sobre la economía y la sociedad. Cita una serie de ejemplos que demuestran que el Estado está más interesado en defender su propio poder que el de sus ciudadanos. Y lanza sus últimos dardos contra la conscripción, como una de las instituciones más deshumanizantes, al convertir al individuo en una «máquina de asesinar» contra «el enemigo más allá de los bordes» que no es otra cosa que un enemigo resultante de la propia invención del Estado y no del individuo per se. 
Nos ha parecido una reflexión con muchas ideas destacables, sobre todo en el tratamiento de las armas de destrucción masiva y el Estado como propiciador de la guerra. Proponemos eso sí, un rediseño de la teoría de la paz, apoyándonos fuertemente en el estudio de las instituciones de la moral, la ética, el derecho y la justicia, como herramientas muy potentes en defensa de las libertades individuales, sin la necesidad de caer en las limitaciones de un axioma a partir del cual no se pueden establecer reglas universales y consistentes para todo tiempo y espacio, por ser una metodología propia de la acción individual y no de los órdenes espontáneos, que regulan la pacífica convivencia de los individuos y estimulan el progreso de sus sociedades.

Habremos cumplido nuestro propósito con la redacción del artículo si despertamos en el lector el interés por un tema tan complejo como polémico como lo es el de la convivencia pacífica en ausencia del monopolio de la justicia por parte del Estado. Y es que más allá del debate económico que ha sido muy bien ganado por la Escuela Austriaca en la Academia, lo que se debate fuera de ella, al momento de hablar de la necesidad de disminuir o incluso suprimir la intervención gubernamental, como consecuencia lógica de los perjuicios que esta institución ocasiona y que la teoría económica nos ilustra, es ¿quién garantizará la paz entre los individuos? De ahí, que se vuelva urgente la necesidad de integrar sólidamente una teoría libertaria que sirva, para todo tiempo y espacio, de marco a un escenario donde prepondere la libertad individual.

Para este cometido, las ideas seminales aquí expuestas son las de revisar la metodología a partir de la cual se quiere elaborar la teoría de la paz, considerando el objeto de estudio, que trasciende lo individual para enmarcarse dentro de los órdenes espontáneos como resultado de la interacción social, analizar formalmente las implicaciones que pudieren tener las teorías elaboradas a partir de un método axiomático lógico-deductivo, el radical cambio de la naturaleza de la guerra en un entorno sin monopolio público de la justicia, y por último, promover los valores transmitidos a través de las diferentes instituciones sociales de origen evolutivo como herramientas que se integren al análisis individual para elaborar una teoría de la paz completa. 


\section{REFERENCIAS BIBLIOGRÁFICAS}

FriedmAn, M. y FriedMAN, R. (1990): Free to Choose: A Personal Statement, Harcourt, San Diego, USA.

HAYEK, F. (2006): Derecho, legislación y libertad, 1. ed., Unión Editorial, Madrid, España.

- (2008): Los fundamentos de la libertad, 8. a ed., Unión Editorial, Madrid, España.

- (2010): La fatal arrogancia: los errores del socialismo, 3. a ed., Unión Editorial, Madrid, España.

Hoppe, H.-H. (2003): The Myth of National Defense, Mises Institute, Alabama, USA.

Huerta DE Soto, J. (2010): Socialismo, cálculo económico y función empresarial, 4. a ed., Unión Editorial, Madrid, España.

LEONI, B. (2010): La libertad y la ley, 3. edición ampliada, Unión Editorial, Madrid, España.

Martínez, C. (2009): La teoría evolutiva de las instituciones: la perspectiva austriaca, 2. ${ }^{\text {a }}$ ed., Unión Editorial, Madrid, España.

Mises, L. von (1998): Human Action: A Treatise on Economics, The Scholar's Edition, Mises Institute, Alabama, USA.

Nozick, R. (1977): Anarchy, State, and Utopia, Basic Books, New York, USA.

Rothbard, M. (1998): The Ethics of Liberty, New York University Press, New York, USA.

Temin, P. (2006): «The Economy of the Early Roman Empire», Journal of Economics Perspectives, vol. 20, n.. 1, winter 2006, pp. 265 290. 
